\title{
The effect of mental workload and work posture on musculoskeletal disorders of Qazvin hospitals, in 2016
}

\author{
Ansari S, MSc ${ }^{1}$, Ataei SS, BSc${ }^{2}$, Varmazyar S, $\mathrm{PhD}^{3^{*}}$, Heydari $\mathrm{P}, \mathrm{MSc}^{1}$ \\ 1- MSc Student in Occupational Health Engineering, Dept. of Occupational Health Engineering, Faculty of Health, Qazvin \\ University of Medical Sciences, Qazvin, Iran. 2- BSc Student in Occupational Health Engineering, Dept. of Occupational \\ Health Engineering, Faculty of Health, Qazvin University of Medical Sciences, Qazvin, Iran. 3- Assistant Prof, Dept. of \\ Occupational Health Engineering, Faculty of Health, Qazvin University of Medical Sciences, Qazvin, Iran.
}

\begin{abstract}
Received: December 2016, Accepted: February 2017

Background: Due to high prevalence of musculoskeletal risk factors among kitchen workers and their role in causing discomfort, the aim of this study was to investigate the effects of ergonomic factors (mental workload and working posture) on musculoskeletal disorders (MSDs) among workers of training hospitals in Qazvin, Iran.

Materials and Methods: This cross-sectional study was done through census among 60 workers of teaching hospital's kitchens of Qazvin University of Medical Sciences in 2016. Data were collected using pain perception and mental workload questionnaires and Quick Exposure Check (QEC) method was used for posture assessment. Data were analyzed using single and multiple logistic regression tests.

Results: About $85 \%$ of the workers reported that their work shift was very heavier than normal. The best and worst exposure score in QEC method were assigned to cooking and trolley responsible tasks, respectively. Seventy percent of working postures were classified in action level 3 (i.e. investigation and changes are required soon) that increased the backache prevalence by nearly about 4 times. Heavy workload in interaction with other influential factors increased the neck discomfort about 5 times and back discomfort by 2.5 times.

Conclusions: Long working hours, heavy workload, stress, high-speed work, long standing and inadequate rest are the factors influencing the increase of MSDs prevalence among the kitchen workers. By increasing numbers of manpower, reducing the workload and working hours and adequate rest, in addition to doing the work properly, MSDs in this group can somehow be reduced.
\end{abstract}

Keywords: Workload, Musculoskeletal Disorders, Hospitals, Iran

\section{Introduction}

Musculoskeletal disorders (MSDs) are injuries that develop in the soft tissue structures of the body such as nerves, muscles, tendons and joints due to repeated or prolonged ergonomic exposures (1). MSDs are the most common occupational injuries $(1,2)$ that can lead to decreased productivity, impose direct and indirect costs on society, and increase the time loss and work-related disabilities (2-5). They are also the main cause for half of absences from work $(6,7)$. Back, neck and shoulders pains and disorders are the main reasons for work-related consultations and have a negative impact on work ability and effectiveness (8).
Musculoskeletal pains are strongly associated with adverse psychological factorsof working environment (9). Working in the kitchen, both in terms of mental workload (services to individuals, working hours, shift work, etc.) and in terms of physical load (lifting heavy pots, bags, etc.) is accounted as a heavy work $(9,10)$. Workload defines as the amount of work that a person is expected to do in a specific time. Thus, the mental workload depends on the relationship between the worker's perception of the task demands and

\footnotetext{
* Corresponding author: Sakineh Varmazyar, Dept. of Occupational Health Engineering, Faculty of Health, Qazvin University of Medical Sciences, Qazvin, Iran. Email: Svarmazyar@qums.ac.ir
} 
their ability to perform and adapt to the work demands. So when reviewing the workload, both mental and physical workload should be considered (11), because the incompatibility of physical and mental capabilities of workers can reduce production, increase safety and health problems and increase compensation and physical discomfort $(6,12)$. So it is expected that musculoskeletal problems can be reduced by optimizing the physical and mental workload (10). According to Haukka's study on kitchen workers, mental factors in the work place are associated with prevalence of musculoskeletal pains (13).

Physical risk factors are such as awkward postures, force, repetition and movement frequency, working time and vibration. From these factors, non-neutral postures are the most important causes of MSDs $(6,14,15)$. Accordingly, the body posture analysis during work is the base of assessing the risk factors of MSDs $(6,14)$. Among the means of assessing the risk of MSDs, posture analysis can be considered as the base of assessment (16). Thus, by identifying the effective risk factors and precise ergonomic risk assessment of these disorders as well as using appropriate methods, the workplace can be improved and the risk of developing MSDs can be reduced (2). One of the methods commonly used for risk assessment of MSDs is QEC (Quick Exposure Check). QEC is a quick and complete method that assesses both physical and psychosocial risk factors in the workplace simultaneously (17-19).

With the progress that has been achieved in preventing manual material handling, still risk assessment in service works such as kitchen were not undertaken in a systematic manner or no assessment has been done (11). According to performed studies on kitchen workers, $75 \%$ of workers had reported body pain in the last year and half of them were receiving medical treatment (20). The study of Kohansal on kitchen workers reported the most disorders in low back, neck and back. Also the posture assessment score for $61.9 \%$ of them was determined in very high risk level and for
$38.1 \%$ was in high risk level (21). Fallah reported the most disorders of kitchen workers in low back (51.7\%), neck (43.7\%) and back (35\%) and QEC risk level showed that workplace condition was harmful (22). In the study of Amini in restaurant's workers, backache was demonstrated the most prevalent MSD (7). Although many has been done by researches in the fields of mental workload investigation and prevalence, posture assessment and prevalence, evaluating the role of each factor separately, few studies have investigated simultaneous effects of mental workload and posture assessment on MSDs disorders among kitchen workers especially in teaching hospitals. The main aim of this study was to investigate the effect of mental workload and working posture on musculoskeletal disorders in kitchen workers in Qazvin training hospitals, Qazvin, Iran.

\section{Material and Methods}

This cross-sectional study was done among 60 kitchen workers of teaching hospitals of Qazvin University of Medical Sciences in 2016. Data were collected using pain perception and workload checklist and posture assessment was done by QEC method. Oral informed consent was taken from participants in the study. Participants were asked not to complete the questionnaire if they had genetic, neurological, and vascular problems in musculoskeletal system. Inclusion criteria were at least 1 year work experience.

Pain perception self-report checklist with the scale of 0-10 was used to investigate the MSDs prevalence. In this checklist, different regions of body are divided to 8 zones including neck, shoulder, elbow, hands/wrists, lower/upper back, thigh, knees and legs/feet. Zero defines as lack of pain, 3 is light pain, 5 is middle pain and 10 means extreme pain (23).

The mental workload perception survey assessed whether the server felt the observed shift was typical of the work demands for the given day and shift. The survey was composed of 6 questions that asked about: 1) how the 
typical shift was relative to the current one being observed (a. significantly lighter than normal, b. slightly lighter than normal, c. typical of normal, d. slightly heavier than normal, e. significantly heavier than normal), 2) How many people they serve per hour on a normal day (a. 1 to 3 people, b. 4 to 6 people, c. 7 to 9 people, d. 10 to 12 people, e. 13 or more people), 3) how many hours a week do they work [a. less than part time (less than 20 hours a week), b. part time (20 hours a week), c. full time (40 hours a week), d. more than 40 hours a week], 4) how long they believe they stand (a. less than an hour, b. greater than an hour but less than 2 hours, c. greater than 2 hours but less than 5 hours, d. greater than 5 hours but less than 8 hours, e. greater than 8 hours), 5) how often they get to take breaks (a. once an hour, b. once a shift, c. whenever you want, d. never), 6) what days do they normally work in a week (a. throughout the entire week b. only weekends, c. only weekdays, d. only mornings, e. only nights) (23). This checklist was translated to Persian and was confirmed by occupational health experts. Scoring the questions was taken as percentage of each item.

QEC method was used for quick assessment of the exposure level of workers with musculoskeletal risk factors. In this method that was presented by $\mathrm{Li}$ and Buckle, the parameters are recorded at the moment that worker is in the worst situation and the postural risk factors and movements are evaluated in four regions of back, neck, hands/wrists and shoulders/arms. Furthermore, to evaluate the mental responses and judgments of employees, they complete a questionnaire containing the maximum displacement load, average displacement time, maximum force exerted by one hand, exposure to vibration, visual needs, speed of work and stress. Body regions exposure level scores based on each region and QEC exposure level with risk factors have been shown in table $1(24,25)$.

Table 1: Exposure level with risk factors and score of any region in Quick Exposure Check

\begin{tabular}{ccccc}
\hline Exposure level & Low & Middle & High & Very high \\
\hline Regions and risk factor & $10-20$ & $21-31$ & $31-40$ & $41-56$ \\
\hline Back & $10-20$ & $21-30$ & $31-40$ & $41-56$ \\
\hline Shoulders and arms & $10-20$ & $21-30$ & $31-40$ & $41-56$ \\
\hline Hands and wrists & $4-6$ & $8-10$ & $12-14$ & $16-18$ \\
\hline Neck & 1 & 4 & 9 & - \\
\hline Vibration & 1 & 4 & 9 & 16 \\
\hline Work speed & 1 & 4 & 9 & - \\
\hline
\end{tabular}

Exposure levels in 4 regions and worker's judgment were imported to QEC software and the results of body posture assessment were obtained. To calculate the exposure score in whole body, score of any region was calculated and then this number was divided by the highest possible score of the whole body. It should be noted that the maximum score for manual material handling tasks is 176 and for other tasks is $162(26,27)$. After assessment through this method, each case was interpreted according to the action levels (AL) described below:
AL1 (E $\leq 40 \%)$ : acceptable musculoskeletal loading,

$\mathrm{AL} 2(41 \%<\mathrm{E}<50 \%)$ : further investigation is needed and changes may be required,

AL3 (51\% < E < 70\%): investigation and changes are required soon,

AL4 $(70 \% \leq \mathrm{E})$ : investigation and immediate change are required $(24,25)$. Validity and reliability of this method has been approved (24).

Data were analyzed using single and multiple logistic regression tests in SPSS (version 20.0, IBM Corporation, Armonk, NY, USA). In 
order to interpret the relationship between dependent and independent variables, we calculated the odds ratio. Odds ratio for dependent variable shows the change in the event of the occurrence to non-occurrence. To determine the significance of the effects of independent variables on the dependent variables in both single and multivariable, we used the $95 \%$ confidence interval for the odds ratio in addition to the possibility of a significant (P-value). If this interval includes the number, the null hypothesis will be confirmed that means no significant independent variable. Otherwise null hypothesis will be rejected and the effect of the independent variable on the dependent variable is significant (28).

\section{Results}

In this study $70 \%$ of workers had service work (chef help and trolley responsible) and 30\% of them were in cooking activities (head-chef and cooker). The mean age \pm standard deviation of participants was reported $38.8 \pm 8.55$ years and mean weight was $69.3 \pm 11.7$ kilogram. Mean, standard deviation and percent of other demographic and occupational variables are presented in table 2 .

Table 2: Demographic, occupational and musculoskeletal disorders prevalence information in Qazvin teaching hospital kitchen workers, Iran, in $2016(n=60)$

\begin{tabular}{|c|c|c|c|c|c|c|}
\hline \multicolumn{3}{|c|}{ Information } & \multirow{3}{*}{$\begin{array}{c}\begin{array}{c}\text { Mean } \pm \text { SD } \\
\text { or percent }\end{array} \\
8.3 \% \\
93.7 \% \\
\end{array}$} & \multicolumn{2}{|c|}{ Information } & \multirow{2}{*}{$\begin{array}{c}\text { Mean } \pm \text { SD } \\
\text { or percent }\end{array}$} \\
\hline \multirow{2}{*}{\multicolumn{2}{|c|}{ Sex }} & Male & & \multirow{2}{*}{ Stress } & Yes & \\
\hline & & Female & & & No & 46.7 \\
\hline \multicolumn{3}{|c|}{ Height (cm) } & $165.9 \pm 8.51$ & \multirow{8}{*}{$\begin{array}{l}\text { Prevalence in } \\
8 \text { body } \\
\text { regions }\end{array}$} & Neck & 45.5 \\
\hline \multicolumn{3}{|c|}{ Body mass index $\left(\mathrm{Kg} / \mathrm{m}^{2}\right)$} & $25.9 \pm 3.82$ & & Shoulder & 41.7 \\
\hline \multirow{2}{*}{\multicolumn{2}{|c|}{$\begin{array}{c}\text { Work experience } \\
\text { (year) }\end{array}$}} & Below 5 & $68.3 \%$ & & Elbow & 6.0 \\
\hline & & More than 5 & $31.6 \%$ & & Hand/wrist & 35.0 \\
\hline \multirow{4}{*}{ Task type } & \multirow{2}{*}{ Cooking } & Head chef & $10 \%$ & & Back & 78.3 \\
\hline & & Chef & $20 \%$ & & Thigh & 11.7 \\
\hline & \multirow{2}{*}{ Service } & Chef help & $43.3 \%$ & & Knee & 39.0 \\
\hline & & Trolley & $26.7 \%$ & & Leg/feet & 10.0 \\
\hline
\end{tabular}

SD: Standard deviation

According to results from investigation of the mental load perception in kitchen workers, $85 \%$ of workers reported their work shift heavier than normal and 15\% reported their work shift normal. All of the workers claimed that they work more than 40 hours in a week, they serve to more than 13 people in a day and stand more than 8 hours in a shift. Also, $51.7 \%$ of the workers rested once in a work shift and $45 \%$ of them never rest. About $23.3 \%$ of the workers reported that they work in all days of a week and $76.7 \%$ of them only work in the nonholiday days.

According to table 3 , the best and worst exposure score in QEC method were assigned to cooking and trolley task, respectively. Among the risk factors, the best and worst state were assigned to cooking tasks (head chef and cooker) and service task (chef help and trolley responsible), respectively. Also the service part was in the action level 3 due to cleaning task, trolley transport and other heavy tasks (table3). According to results of QEC method, 20 percent of the personnel were in action level 1 (below 40\%), 10 percent in action level 2 (between 41\%-50\%) and 70 percent in action level 3 (between 51\%-70\%). 
Table 3: Exposure level score in 4 regions and risk factors based on calculated score in Qazvin teaching hospital kitchen workers, Iran, in 2016

\begin{tabular}{|c|c|c|c|c|c|c|c|c|c|c|}
\hline Task type & Regions & Low & Middle & High & $\begin{array}{l}\text { Very } \\
\text { high }\end{array}$ & $\begin{array}{l}\text { Exposure } \\
\text { level } \\
\text { Risk } \\
\text { factors }\end{array}$ & Low & Middle & High & $\begin{array}{l}\text { Very } \\
\text { high }\end{array}$ \\
\hline \multirow{7}{*}{ Head chef } & Low back & & 22 & & & Vibration & 1 & & & \\
\hline & Shoulder/arm & & 22 & & & $\begin{array}{c}\text { Speed of } \\
\text { work }\end{array}$ & & 4 & & \\
\hline & Hand/wrist & & 22 & & & Stress & & 4 & & \\
\hline & Neck & 6 & & & & & & \multirow{4}{*}{ - } & & \\
\hline & Who & body & exposure & $\mathrm{vel}$ & & & & & & \\
\hline & Exposure level & & $\mathrm{N}$ & $\mathrm{Pel}$ & & & & & & \\
\hline & 2 & & 6 & & & & & & & \\
\hline \multirow{7}{*}{ Chef } & Low back & 14 & & & & Vibration & 1 & & & \\
\hline & Shoulder/arm & & 22 & & & $\begin{array}{l}\text { Speed of } \\
\text { work }\end{array}$ & & 4 & & \\
\hline & Hand/wrist & & 22 & & & Stress & & 4 & & \\
\hline & Neck & 6 & & & & & & \multirow{4}{*}{-} & & \\
\hline & Who & body & exposure & vel & & & & & & \\
\hline & Exposure level & & $\mathrm{N}$ & $\mathrm{Pel}$ & & & & & & \\
\hline & 1 & & 12 & & & & & & & \\
\hline \multirow{7}{*}{ Chef help } & Low back & & 30 & & & Vibration & 1 & & & \\
\hline & Shoulder/arm & & 30 & & & $\begin{array}{l}\text { Speed of } \\
\text { work }\end{array}$ & & 4 & & \\
\hline & Hand/wrist & & & 36 & & Stress & & & 9 & \\
\hline & Neck & 8 & & & & & & \multirow{4}{*}{ - } & & \\
\hline & Who & body & exposure & vel & & & & & & \\
\hline & Exposure level & & $\mathrm{N}$ & $\mathrm{Pel}$ & & & & & & \\
\hline & 3 & & 26 & & & & & & & \\
\hline \multirow{7}{*}{$\begin{array}{l}\text { Trolley } \\
\text { responsible }\end{array}$} & Low back & & & 34 & & Vibration & 1 & & & \\
\hline & Shoulder/arm & & & 36 & & $\begin{array}{l}\text { Speed of } \\
\text { work }\end{array}$ & & & 9 & \\
\hline & Hand/wrist & & & 32 & & Stress & & & 9 & \\
\hline & Neck & & 10 & & & & & \multirow{4}{*}{-} & & \\
\hline & \multicolumn{5}{|c|}{ Whole body exposure level } & & & & & \\
\hline & Exposure level & & $\mathrm{N}$ & & & & & & & \\
\hline & 3 & & 16 & & & & & & & \\
\hline
\end{tabular}

The results of investigating the effective risk regions based on single and multiple logistic factors on MSDs in neck, shoulder and back regression tests have been shown in table 4 .

Table 4: Investigating the effective risk factors on musculoskeletal disorders based on single and multivariate regression test in Qazvin teaching hospital kitchen workers, Iran, in 2016

\begin{tabular}{|c|c|c|c|c|c|c|c|}
\hline \multirow[b]{2}{*}{$\begin{array}{l}\text { Risk } \\
\text { factor }\end{array}$} & \multirow[b]{2}{*}{$\begin{array}{l}\text { Scale or } \\
\text { category }\end{array}$} & \multicolumn{2}{|c|}{ Neck } & \multicolumn{2}{|c|}{ Shoulder } & \multicolumn{2}{|c|}{ Back } \\
\hline & & $\begin{array}{c}\text { Single } \\
(95 \% \mathrm{CI})\end{array}$ & $\begin{array}{c}\text { Multivariate } \\
(95 \% \text { CI })\end{array}$ & $\begin{array}{c}\text { Single } \\
(95 \% \mathrm{CI})\end{array}$ & $\begin{array}{c}\text { Multivariate } \\
(95 \% \mathrm{CI})\end{array}$ & $\begin{array}{c}\text { Single } \\
(95 \% \mathrm{CI})\end{array}$ & $\begin{array}{c}\text { Multivariate } \\
(95 \% \text { CI })\end{array}$ \\
\hline \multirow{4}{*}{$\begin{array}{l}\text { Task } \\
\text { type }\end{array}$} & Chef & 1 & 1 & 1 & 1 & 1 & 1 \\
\hline & Head chef & $\begin{array}{c}0.7 \\
(0.09-5.43)\end{array}$ & $\begin{array}{c}0.8 \\
(0.01-35.20)\end{array}$ & $\begin{array}{c}0.7 \\
(0.09-5.43)\end{array}$ & $\begin{array}{c}0.12 \\
(0.003-5.59)\end{array}$ & $\begin{array}{c}0.66 \\
(0.07-5.68)\end{array}$ & $\begin{array}{c}0.03 \\
(0.0-23.21)\end{array}$ \\
\hline & Chef help & $\begin{array}{c}0.87 \\
(0.21-3.52) \\
\end{array}$ & $\begin{array}{c}2.22 \\
(0.12-38.20)\end{array}$ & $\begin{array}{c}0.87 \\
(0.21-3.52)\end{array}$ & $\begin{array}{c}0.08 \\
(0.005-1.57)\end{array}$ & $\begin{array}{c}0.63 \\
(0.13-2.92) \\
\end{array}$ & $\begin{array}{c}1.71 \\
(0.14-20.50)\end{array}$ \\
\hline & $\begin{array}{c}\text { Trolley } \\
\text { responsible }\end{array}$ & $\begin{array}{c}2.33 \\
(0.50-10.80) \\
\end{array}$ & $\begin{array}{c}6.27 \\
(0.16-240.50) \\
\end{array}$ & $\begin{array}{c}2.33 \\
(0.50-10.77) \\
\end{array}$ & $\begin{array}{c}4.6 \\
(0.02-13.05) \\
\end{array}$ & $\begin{array}{c}2.33 \\
(0.32-16.80) \\
\end{array}$ & $\begin{array}{c}8.05 \\
(0.34-190.5) \\
\end{array}$ \\
\hline \multirow{4}{*}{$\begin{array}{c}\text { Whol } \\
\text { e } \\
\text { body } \\
\text { QEC }\end{array}$} & $\begin{array}{c}\text { Exposure } \\
\text { level1 }\end{array}$ & 1 & 1 & 1 & 1 & 1 & 1 \\
\hline & $\begin{array}{l}\text { Exposure } \\
\text { level2 }\end{array}$ & $\begin{array}{l}0.7(0.09- \\
5.43)\end{array}$ & - & $\begin{array}{c}0.7 \\
(0.09-5.43)\end{array}$ & - & $\begin{array}{c}0.66 \\
(0.07-3.67)\end{array}$ & - \\
\hline & $\begin{array}{c}\text { Exposure } \\
\text { level3 }\end{array}$ & $\begin{array}{c}0.27 \\
(0.34-2.65) \\
\end{array}$ & - & $\begin{array}{c}0.27 \\
(0.34-2.65) \\
\end{array}$ & - & $\begin{array}{c}3.93(0.21- \\
5.11)\end{array}$ & - \\
\hline & $\begin{array}{l}\text { Exposure } \\
\text { level4 }\end{array}$ & - & - & - & - & - & - \\
\hline
\end{tabular}




\begin{tabular}{|c|c|c|c|c|c|c|c|}
\hline \multirow[t]{2}{*}{ Stress } & Yes & $\begin{array}{c}0.89 \\
(0.32-2.48) \\
\end{array}$ & $\begin{array}{c}1.95 \\
(0.20-18.70)\end{array}$ & $\begin{array}{c}0.89 \\
(0.32-2.48) \\
\end{array}$ & $\begin{array}{c}0.29 \\
(0.03-2.42) \\
\end{array}$ & $\begin{array}{c}1.69 \\
(0.53-5.36) \\
\end{array}$ & $\begin{array}{c}4.6 \\
(0.67-31.60)\end{array}$ \\
\hline & No & 1 & 1 & 1 & 1 & 1 & 1 \\
\hline \multirow[b]{2}{*}{$\begin{array}{l}\text { Work } \\
\text { load }\end{array}$} & Normal & 1 & 1 & 1 & 1 & 1 & 1 \\
\hline & Heavy & $\begin{array}{c}0.44 \\
(0.40-7.89)\end{array}$ & $\begin{array}{c}4.88 \\
(0.28-84.30)\end{array}$ & $\begin{array}{c}0.44 \\
(0.40-7.89)\end{array}$ & $\begin{array}{c}0.37 \\
(0.03-4.21)\end{array}$ & $\begin{array}{c}1.46 \\
(0.31-6.69)\end{array}$ & $\begin{array}{c}2.35 \\
(0.02-5.02)\end{array}$ \\
\hline \multirow{2}{*}{$\begin{array}{c}\text { Rest } \\
\text { chanc } \\
\text { e }\end{array}$} & $\begin{array}{c}\begin{array}{c}\text { Once in } \\
\text { shift }\end{array} \\
\end{array}$ & 1 & 1 & 1 & 1 & 1 & 1 \\
\hline & Never & $\begin{array}{c}0.75 \\
(0.27-2.09) \\
\end{array}$ & $\begin{array}{c}0.05 \\
(0.003-1.05) \\
\end{array}$ & $\begin{array}{c}0.75 \\
(0.27-2.09) \\
\end{array}$ & $\begin{array}{c}0.18 \\
(0.01-2.19) \\
\end{array}$ & $\begin{array}{c}0.64 \\
(0.20-2.05) \\
\end{array}$ & $\begin{array}{c}0.06 \\
(0.005-0.06) \\
\end{array}$ \\
\hline \multirow{2}{*}{$\begin{array}{l}\text { Work } \\
\text { days }\end{array}$} & $\begin{array}{c}6 \text { days in a } \\
\text { week }\end{array}$ & 1 & 1 & 1 & 1 & 1 & 1 \\
\hline & $\begin{array}{c}7 \text { days in a } \\
\text { week }\end{array}$ & $\begin{array}{c}2.8 \\
(0.80-9.70)\end{array}$ & $\begin{array}{c}5.66 \\
(0.07-32.90)\end{array}$ & $\begin{array}{c}2.8 \\
(0.80-9.70)\end{array}$ & $\begin{array}{c}5.45 \\
(0.29-28.50)\end{array}$ & $\begin{array}{c}2.56 \\
(0.15-4.04)\end{array}$ & $\begin{array}{c}21.8 \\
(0.21-29.40)\end{array}$ \\
\hline
\end{tabular}

Hosmer-Lemeshow goodness-of-fit; Multivariable: neck (0.607), shoulder (0.415) and back (0.592).

Hosmer-Lemeshow goodness-of-fit; Single: 1.00.

QEC: Quick Exposure Check; CI: Confidence interval

\section{Discussion}

in this study, all of the workers (100\%) worked in standing state during the whole shift, whereas in the study of Pekkarinen $78 \%$ of workers were in a standing posture (29). Also, $85 \%$ of workers in this study, reported their work shift heavier than normal that with attention to regression result, heavy workload interaction with other risk factors can increase the neck and back pain by 4.8 and 2.3 times, respectively. More than $50 \%$ of these workers rested just once during the shift and $45 \%$ of them did not have any rest. In the study of Wills, $60 \%$ of restaurant workers reported their shift easier than normal and $40 \%$ of them rest once along the shift. This result regarding the opportunity to rest is in line with current study, but with regard to workload is in conflict with current study (23).

In this study, the most prevalent disorder was reported in the low back region that is in line with studies of Wills (23), Amini (7) and Kohansal (21). After the low back, regions with high prevalence of disorders were neck, shoulder and knees. Of reasons of high prevalence of low back and knee pain can be the long hours of standing work with $100 \%$ worker's response and heavy workload with $85 \%$ response. Other reason can be inadequate rest during shift, because just $3.3 \%$ of workers could rest when they would like and other workers did not have rest or had just one rest and in this short time, naturally one would not be able to sit and rest appropriately.

Whole body score in QEC method showed that the level 3 had the highest frequency. This suggests that more study and corrective actions in near future is necessary. In the study of Kohansal, $61.9 \%$ of kitchen workers were in action level 4 (21). This difference in the findings can be due to number of employees, more servicing, shift work, number of hospital sections to servicing and etc.

In present study, posture of trolley responsible and help-chef were in action level 3. Also score of back posture was high and it can be derived that the corrective action should be taken in near future in these tasks. According to regression test, workers that were in action level 3 were susceptible to backache by 3.9 times. Increasing the manpower, taking the rest time and using trolley device with adjustable height to avoid continuous bending of back, neck and shoulder are from suggested corrective actions to decrease exposure risk level and MSDs. Kohansal stated the help-chef task in level 3 that is consistent with this study (21).

In the current study, exposure level score and prevalence of pain in neck for trolley responsible showed the highest risk. High level of discomfort in this region can be linked with repeated bending and twisting of it when dragging cover on dishes and putting the food containers into the different stages of trolley. 
The highest prevalence of shoulder pain was reported in cooker and trolley responsible that its reason could be mixing food frequently with large mixer and pushing the heavy trolleys (more than $100 \mathrm{~kg}$ ). This results are in line with researches of Fallah (22) and Kohansal (21) regarding the high prevalence of neck, shoulder pain and QEC level.

Among the tasks, trolley responsible was in risk of MSDs about 2 times more than others and in interaction with other risk factors, this amount reached up to 8 times. Also chef help was in risk of neck and back pain by 2.2 and 1.7 times, respectively. Thus, it can be concluded that hard work increases the backache. Trolley responsible was in risk of neck and shoulder pain about 2 times more and in interaction with other risk factors, the prevalence of neck and shoulder disorder became 6.2 and 4.6 times higher, respectively.

Long working hours, high workload and inadequate rest are factors that affect MSDs in kitchen workers. Working in all days of week, based on single and multivariate regression test, increased neck and shoulder pain by 2.8 and 5.4 times, respectively and increased the backache by 2.5 and 21.8 times. Amini reported the long work time and long-term standing as the reasons of MSDs (7). Therefore, with increasing the number of manpower, reducing the workload and working hours and adequate rest, proper selection of personnel fitness with task type, and work rotation, in addition to proper handling of the work and observing the work origins, MSDs can be reduced the in this group. Also, with regard to high risk of discomfort in trolley responsible, the exposure risk level can be reduced with decreasing the weight of trolley in each servicing and designing a light trolley device with adjustable height. In cookers, light mixers can be used to reduce the mixing force. Stress was reported in more than $50 \%$ of the workers and can be due to the activity type, services and work pressure. Stress alone can increase the backache by 2 times and by 4.6 times in interaction with other factors. Serving a huge number of hospital personnel and patients and high work speed can be the reasons for stress. In this study, the work speed for trolley responsible was reported in high state. In study of Sarsangi, the work speed and stress was reported very high in 50\% of workers that is in line with current study (26).

\section{Conclusion}

Long working hours, high workload, stress, high work speed, long-term working in the standing state and inadequate time for rest are among the factors owing to the high prevalence of MSDs in kitchen workers. The limitations of this study were low sample size and not investigating the whole employees of kitchens such as restaurants, self-services in universities and etc. So, is suggested that in future studies in addition to performed assessments in this study, the lifting permissible limit evaluation to be done too.

\section{Acknowledgements}

This study was prepared and conducted in the teaching hospital affiliated to Qazvin University of Medical Sciences, so the authors would like to thank the hospital officials and kitchen workers who cooperated in this research.

Conflict of interest: None declared.

\section{References}

1. Karwowski W. International encyclopedia of ergonomics and human factors. 1st ed. Boca Raton, Florida, United States: CRC Press; 2001. (Vol 3).

2. Gholami A, Soltanzadeh A, Abedini R, Sahravand M. Ergonomic assessment of musculoskeletal disorders risk by rapid upper limb assessment (RULA) technique in a porcelain manufactring factory. Journal of Research \& Health 2014; 4(1):608-12.

3. Soltani R, Dehghani Y, Sadeghi Naeini H, Falahati M, Zokaee M. The welders posture assessment by OWAS technique. Occupational Medicine Quarterly Journal 2011; 3(1):34-9.

4. Azizi M, Baroonyzadeh Z, MotamedzadeM. Working postures assessment using RULA and 
ergonomic interventions in quality control unit of a glass manufacturing company. Journal of Ergonomics 2013; 1(1):73-9.

5. Nasle Saraji J, Ghafari M, Shahtaheri SJ. Survey of correlation between two evaluation methods of work related musculoskeletal disorders risk factors REBA \& RULA. Iran Occupational Health Journal 2006; 3(2):25-32.

6. Mostaghasi M, Davari MH, Mollaei F, Salehi M, Mehrparvar AH. Evaluation of the frequency of musculoskeletal disorders and work posture analysis by RULA method in workers of an auto- part manufacturing company. Occupational Medicine Quarterly Journal 2012; 3(4):26-32.

7. Amini A, Sazandeh Z, Varmazyar S. Assessment of Musculoskeletal Disorders (MSDS) in workers of Qazvin restaurants. Paper presented at: The $9^{\text {th }}$ National Congress Occupational Health and Safety; 2015 June 1011; Yazd, Iran.

8. Haukka E, Leino Arjas P, Solovieva S, Ranta R, Viikari Juntura E, Riihimiaki H. Cooccurrence of musculoskeletal pain among female kitchen workers. Int Arch Occup Environ Health 2006; 80(2):141-8.

9. Haukka E, Ojajarvi A, Takala E, Viikari Juntura E, Leino Arjas P. Physical workload, leisure-time physical activity, obesity and smoking as predictors of multisite musculoskeletal pain. A 2-year prospective study of kitchen workers. Occupational and Environmental Medicine 2012; 69(7):485-92.

10. Pehkonen I, Takala EP, Ketola R, ViikariJuntura E, Leino Arjas P, Hopsu L, et al. Evaluation of a participatory ergonomic intervention process in kitchen work. Appl Ergon 2009; 40(1):115-23.

11. Chim J. Ergonomics workload analysis for the prevention of musculoskeletal disorders in food services in the health sector. Human Factors \& Ergonomics Society of Australia $42^{\text {nd }}$ Annual Conference; 2006; Australia.

12. Habibi E, Dehghan H, Zeinodini M, Yousefi H, Hasanzadeh A. A study on work ability index and physical work capacity on the base of fax equation $\mathrm{VO}_{2}$ max in male nursing hospital staff in Isfahan, Iran. Int J Prev Med 2012; 3(11):776-82.

13. Haukka E, Leino-Arjas $P$, Ojajärvi A, Takala EP, Viikari-Juntura E, Riihimäki H. Mental stress and psychosocial factors at work in relation to multiple-site musculoskeletal pain: a longitudinal study of kitchen workers. Eur J Pain 2011; 15(4):432-8.

14. Zamanian $\mathrm{Z}$, daneshmandi $H$, Setoodeh $\mathrm{H}$, Nazaripoor E, Haghyegh A, Sarvestani SS. Risk assessment of musculoskeletal disorders and determination of the associated factors among workers of a dairy products factory. Journal of Health Sciences and Surveillance System 2014; 2(4):134-9.

15. Varmazyar S, Amini M, Kiafar M. Ergonomic evaluation of work condition in Qazvin dentists by REBA method and its association with musculoskeletal disorders in 2008. J Islam Dent Assoc Iran 2012; 24(3):229-37.

16. Mohammadfam I, Kianfar A, Afsartala B. Assessment of musculoskeletal disorders in a manufacturing company using QEC and LUBA methods and comparison of results. Iran Occupational Health 2010; 7(1):54-60.

17. Abedini R, Choubineh AR, Soltanzadeh A, Ghiasvand R, Haghighi MK. Ergonomic evaluation of exposure to musculoskeletal disorders risk factors by Quick Exposure Check (QEC) technique in a metal structure manufacturing factory. Jundishapur Journal of Health Sciences 2012; 4(2):13-20.

18. Chiasson MÈ, Imbeau D, Aubry K, Delisle A. Comparing the results of eight methods used to evaluate risk factors associated with musculoskeletal disorders. Int $\mathrm{J}$ Ind Ergon 2012; 42(5):478-88.

19. Abdollahpour N, Helali F, Ziaei M, Hamzeian M, Keikhamoghaddam AA, Gholamnia R ea. Assessment of risk factors and the prevalence of musculoskeletal disorders by QEC and body map operational units of the Gas refinery in Iran and its meta-reflection. Journal of Health 2016; 7(1):33-50.

20. Mitchell T. Someone's in the kitchen. The ergonomics of cooking and kitchen design [Internet]. 2011 [cited 2011 November 20]. Available from: http://www.workingwell.org/articles/pdf/Cooking_2017.pdf

21. Kohansal S, Kohpaei AR, Gharlipor Gharg Z, Habibi P, Ziaei M, Gilasi H, et al. Ergonomic evaluation of musculoskeletal disorders among kitchen workers by QEC technique in the Tehran University of Medical Sciences. Journal of Ilam University of Medical Sciences 2013; 20(5):18-23.

22. Fallah H, Koohnavard B, Cheraghi M, Yousefi M. Evaluation of ergonomic to quickly assess exposure method in the dining hall workers of the University of Medical Sciences in 2014. Paper presented at: The $1^{\text {st }}$ Biennial Iranian Conference on Ergonomics; 2015 October 1516; Hamedan, Iran.

23. Wills AC. Musculoskeletal disorder risk factor assessment in restaurant servers. [BS thesis]. Cincinnati, OH 45220, USA: University of Cincinnati; 2010.

24. Keikhamoghaddam AA. Ergonomics evaluation methods: Guide of Selection and 
Application (Physical evaluation methods). $1^{\text {st }}$ ed. Tehran: Fanavaran publisher; 2013. P.3948.

25. Choobine AR. Methods of posture assessment in occupational ergonomics. $1^{\text {st }}$ ed. Tehran: Fanavaran publisher; 2013. P.111-31.

26. Sarsangi V, Motallebi Kashani M, Fallah H, Zarei E, Khajevandi A, Saghi $\mathrm{MH}$, et al. Detection and risk assessment of musculoskeletal disorders among the staffs employed in a dish manufacturing company using the QEC method and Nordic questionnaire. Journal of Sabzevar University of Medical Sciences 2014; 20(5):706-15.
27. Choobineh AR, Mokhtarzadeh A, Salehi M, Tabatabaei HR. Ergonomic evaluation of exposure to musculoskeletal disorders risk factors by QEC technique in a rubber factory. Jundishapur Scientific Medical Journal 2008; 7(1):46-55.

28. Habibpour Gatabi K, SafariShali R. Comprehensive guide uses SPSS in survey research (quantitative data analysis). $1^{\text {st }}$ ed. Tehran: Looyeh-Motefakeran 2013. P.713-37.

29. Pekkarinen A, Anttonen H. The effect of working height on the loading of the muscular and skeletal systems in the kitchens of workplace canteens. Appl Ergon 1988; 19(4):306-8. 